\title{
Problems in the Diagnosis of Progressive Supranuclear Palsy
}

\author{
(Steele - Richardson - Olszewski Syndrome)
}

\author{
GEORGE DAVID PERKIN, ANDREW JOHN LEES, GERALD MALCOLM STERN AND ROMAN STEFAN KOCEN
}

SUMMARY: Five patients with progressive supranuclear palsy are described, in whom the ophthalmoplegia developed late in the course of the disease. In two, an internuclear component was identified in the ophthalmoplegia, and one patient had an alternating nystagmus of a type not previously described in this condition.

The late appearance of the ophthalmoplegia, with a corresponding delay in establishing the diagnosis, is compared to the similar experience of Pfaffenbach et al (1972) in six patients.

Other clinical features, previously seldom described, have been encountered. Dysphasia was seen in two cases, both of whom had evidence of cortical atrophy on neuro-radiological investigation. The evidence that cortical changes, in particular the presence of neurofibrillary tangles, may be a specific morphological characteristic of the disease

RÉSUMÉ: Nous décrivons 5 patients avec paralysie supranucléaire progres. sive chez qui l'ophtalmophlégie s'est développé tardivement dans l'évolution de la maladie. Chez deux de ces patients nous avons identifié une composante internucléaire dans l'ophtalmoplégie. Un autre patient présenait un nystagmus alternatif d'un type non préalablement décrit dans cette condition.

$D^{\prime}$ autres aspects peu connus furent également observés. Ainsi on note une dysphasie chez deux cas qui tous deux présentaient en neuroradiologie de l'évidence d'atrophie corticale. Cet aspect cortical, ainsi que la présence de formations neurofibrillaires comme charactéristique de la maladie, fait l'objet d'une discussion. Chez 4 patients il y avait des troubles du rythme re-

From the Charing Cross, Middlesex and University College Hospitals and the National Hospitals for Nervous Diseases, London.

Reprint requests to Dr. G. D. Perkin, Charing Cross Hospital, Fulham Palace Road, London W6 8RF England. rather than a chance association is discussed. Disorders of respiratory rhythm in four patients were similar to those described by Mastaglia et al. (1973), and indistinguishable from those occurring after encephalitis lethargica.

$A$ review of cases resembling progressive supranuclear palsy in the early part of the century fails to show any with post-encephalitic features, nor does a search of reviews of eye movement disorders in encephalitis lethargica and post-encephalitic Parkinsonism provide comparable cases. None of the forty patients with post encephalitic Parkinsonism examined at the Highlands Hospital had a clinical picture resembling progressive supranuclear palsy.

It is suggested that neither on clinical nor pathological grounds is it justifiable to equate this disorder with known postencephalitic syndromes.

spiratoire semblables à ceux observés dans l'encéphalite léthargique.

Une revue de la littérature du début du siècle concernant les cas ressemblant à la paralysie supranucléaire progressive n'a pas révélé d'association avec des composantes post-encéphalitiques. Nous n'avons pas non plus retrouvé de semblables troubles oculaires dans l'encéphalite léthargique ou le Parkinsonisme post-encéphalitique. 40 patients avec Parkinson post-encéphalitique furent étudiés au Highlands Hospital. Aucun ne présentait le tableau clinique de la paralysie supranucléaire progressive. Il semble donc qu'il n'est nullement justifié, cliniquement ou pathologiquement, d'assimiler ces cas avec les syndromes post-encéphalitiques connus.

\section{INTRODUCTION}

A particular ophthalmoplegia is an integral part of the SteeleRichardson-Olszewski syndrome (1963). Although described by Pfaffenbach et al. (1972), it has not been fully appreciated that this ophthalmoplegia may occur relatively late in the course of the disease. This paper records five cases, two of whom, in addition, showed a more complex ophthalmoplegia than has been generally recognized.

The problem of differential diagnosis has led to an appraisal of progressive supranuclear palsy as a clinical entity, including its relationship to post-encephalitic Parkinson's disease.

\section{CASE REPORTS}

1. BS $1507 \mathrm{NH}$ A85854 A 54-year-old housewife presented in 1969 with a two year history of speech difficulties, impaired balance, and clumsiness of the hands. On examination, intellectual function appeared intact. The gait was normal apart from a reduced arm swing. Cranial nerve examination showed a paucity of facial expression with a mild left-sided weakness, intermittent lid retraction, and a positive glabellar tap. External ocular movements were normal. Her speech was dysarthric.

Mild rigidity and bradykinesia were present in the upper limbs, with brisk deep tendon reflexes and extensor plantar responses bilaterally.

Air encephalography and spinal fluid examination were normal.

Anti-cholinergic and subsequently L-Dopa therapy in doses reaching $5 \mathrm{~g}$ daily failed to improve her disabilities, and subsequent trials of amantidine and dopa with a dopa decarboxylase inhibitor were equally unsuccessful. By 1973, she was severely dysarthric, with axial and limb rigidity and a slow broad-based gait. Oculomotor function remained normal. From September, 1975 she began to complain of difficulty with reading and seeing objects immediately in front of her, and her relatives noticed periodic alterations in her breathing pattern. 
On examination, her gait was broad based with a tendency to fall backwards. Cranial nerve examination revealed an expressionless face, with bilateral facial weakness and intermittent lid retraction. Visual fields and acuities were normal. Ocular movements to command in the vertical plane were absent, and following movements were restricted to $5^{\circ}$ upwards. Horizontal movements were slow, with evidence of a left internuclear ophthalmoplegia. Convergence was absent. Doll's head maneuvre caused an improvement in the range of vertical gaze and appeared to abolish the internuclear component. She was severely dysarthric with a brisk jaw jerk and poor tongue movements. The remaining cranial nerves were normal, though periodic sighs were observed. Nuchal and limb rigidity were prominent, with a lesser degree of bradykinesia. The deep tendon reflexes were again brisk, and the plantar responses remained extensor. In addition to her immobility, she had difficulty rising from a sitting position.

Formal psychometry revealed no overt dementia, though assessment was difficult.

Neuro-otological examination was carried out at the National Hospital for Nervous Diseases, Queen Square, London, and the findings (together with those of the other three patients who were similarly assessed) are summarised in Table 1 .

Subsequent treatment with the dopamine agonist, bromocriptine, in a dose of $90 \mathrm{mg}$ daily, failed to influence the clinical picture. 2. AX $0805 \mathrm{NH}$ A86296 This 63-year-old housewife presented in 1967, complaining of stiffness of the legs, poor balance, and clumsiness. Examination revealed a Parkinsonian facies, cogwheel rigidity in the left arm, and intermittent retropulsion. Over the next two years, her gait became increasingly disorganized with frequent falls. A diagnosis of Parkinson's disease appeared to be corroborated when, in 1970, modest improvement occurred with L-Dopa in a dose of $4 \mathrm{~g}$. daily. Additional anti-cholinergic therapy was unhelpful, and her disabilities increased. An ophthalmoplegia was not observed at this stage.

From April, 1975, she complained of watering of the eyes and poor vision. On examination, six months later, she had a slow and broadbased gait with a tendency to veer to the left. Her face was immobile. Visual acuities were $6 / 9$ right and $6 / 12$ left, with normal fields and fundi. Eye movements were abnormal. Following and command movements were $\mathrm{li}$ mited to $5^{\circ}$ in the vertical plane. Horizontal eye movements were slow and poorly sustained, with a left internuclear ophthalmoplegia. Convergence was absent. Horizontal eye movements were accompanied by bursts of oscillatory nystagmus. Doll's head maneuvre improved the range of vertical gaze. She was severely dysarthric and had a brisk jaw jerk. There were frequent sighs.

Nuchal and limb rigidity were present with moderate bradykinesia but no weakness nor tremor. She had difficulty rising from a sitting position.

Formal psychometric examination showed no evidence of dementia.
Treatment with bromocriptine, $70 \mathrm{mg} / \mathrm{day}$. led to a moderate improvement in her speech and bradykinesia, but was without effect on the abnormal eye movements.

3. MV 76783 This 58 -year-old housewife was seen in September, 1973 with a year's history of shaking and clumsiness of the right hand. Her right leg began to shake, particularly when walking, and she had difficulty producing the correct words in conversation. Sudden falls had occurred, sometimes with injury, and she had become increasingly forgetful.

On examination, she appeared demented and made dysphasic errors in conversation. Her gait was mildly ataxic, with a reduced right arm swing and a tendency to drag the right leg. She had a Parkinsonian facies. Horizontal and vertical eye movements were slowed both to command and on pursuit, but were of full range. Convergence was absent. There was a questionable right facial weakness and a delayed shrug of the right shoulder. Tongue movements were impaired, and the neck was rigid.

Fine movements were slowed in the upper limbs, particularly on the right, and all four limbs showed moderate rigidity. The deep tendon reflexes were pathologically brisk, with bilateral extensor plantar responses. No definite abnormalities of sensation were detected.

Electro-encephalography revealed nonspecific bilateral abnormalities. Air encephalography demonstrated dilated parietal and superior cerebellar sulci. The cerebrospinal fluid was normal.

Formal psychometric examination confirmed a moderate degree of dementia, with some degree of dysphasia as the most prominent defect.

Trials of L-Dopa and L-Dopa with a dopa decarboxylase inhibitor were unsuccessful in preventing the subsequent deterioration of the patient's condition. Within two years, a characteristic ophthalmoplegia had developed. By then, vertical eye movements were restricted to $20^{\circ}$ of elevation on pursuit. Command and pursuit movements in the horizontal plane were slowed and restricted. Oculocephalic responses were full.

The patient's general condition had deteriorated further in this period, and over the next year her husband noted a disturbance of respiratory control with episodic sighs.

4. MV 76838 NH A74662 A 70-year-old retired butcher was admitted to Maida Vale Hospital in 1973. He had been involved in a road traffic accident in 1970 , and had a brief loss of consciousness but no retrograde amnesia. His behavior changed subsequently. He became emotionally labile, withdrawn, and less able to carry out repairs in his home. $\mathrm{He}$ accused his wife of trying to poison him and was eventually admitted to hospital for twelve weeks. During this time, he received electroconvulsive therapy on five occasions and was treated with trifluoperazine and isocarboxazid.

There was little response to this treatment, nor to the subsequent use of Cyclandelate (a proprietary preparation of dihydroergocornine, dihydroergocristine and dihydroergokryptine) and Hydergine (dihydroergotoxine mesylate). He became less mobile, with clumsiness of the hands, and was liable to lose himself even at home. Paranoid ideas continued, and he was visually hallucinated at times.

Examination in August, 1973 showed a marked slowing of thought, with dysarthria and an immobile face. A right ptosis was present but eye movements were normal. Cogwheel rigidity was present in all four limbs. His condition deteriorated further, and he was admitted to hospital four months later.

He had become disorientated in place and time and had little knowledge of recent events. His speech content was often irrelevant, and he made naming errors. His gait was slowed, with a stooped posture and fixed, flexed arms. There was a poor range of facial expression and bilateral ptosis.

The most striking change was apparent on assessing eye movements. Command and following movements were absent in the vertical plane upwards and severely limited downwards. Convergence was absent. Horizontal movements were slowed, but full, apart from incomplete left lateral gaze to command. Oculocephalic responses were full, though a marked degree of nuchal rigidity in all directions of movement made the maneuvre difficult.

Cogwheel rigidity was present bilaterally, and fine finger movements were slowed. There was no significant limb weakness, the deep tendon reflexes were normal, and the plantar responses flexor. No sensory abnormalities were detected.

Electroencephalography showed a generalised abnormality, with a slowed alpha rhythm and widespread intermediate slow wave activity. Focal delta activity in the right midtemporal region was noted.

Psychometric assessment showed evidence of a dementia without focal feature.

The patient was readmitted two years later. His walking had deteriorated, with frequent falls and his speech was often unintelligible. $\mathrm{He}$ had frequent urinary incontinence.

Examination confirmed the progression of his disability. His speech was confused and episodic. There was gross nuchal rigidity. Vertical gaze to command or pursuit was absent, as was left lateral gaze. Occasional full gaze to the right was elicited, though cooperation was imperfect. The remainder of the examination confirmed the findings previously obtained, though to an accentuated degree.

The electroencephalogram had deteriorated. Widespread slow wave complexes were followed by brief periods of suppression of background activity. Computerised axial tomography showed evidence of ventricular dilatation.

The patient's condition was unaffected by a trial of bromocriptine in a dose reaching $25 \mathrm{mg}$ daily. He died six years after the onset of neurological symptoms. Permission for post-mortem examination was refused.

5. MV 60796 This 59-year-old housewife was admitted to the Maida Vale Hospital in 1976. In 1966, she had been seen in the outpatient department with a month's history of headache and unsteadiness on head movements. Neurological examination was normal, 
but she appeared depressed and was treated accordingly. The depression recurred, however, and eventually led to admission to a psychiatric hospital in 1973. She had become indecisive and excessively self-critical. and failing to respond to amitriptyline, received a course of electroconvulsive therapy. The clinical picture then changed; she regressed, became self-neglectful, and had difficulty finding her way in the hospital. She presented a Parkinsonian appearance and was referred to a consultant neurologist at another hospital. Examination there, in August, 1973, revealed a mask-like facies, with cogwheel rigidity in the right arm and leg. Eye movements were normal. An electroencephalogram revealed no abnormalities.

Treatment with benzhexol appeared to improve her general state temporarily, but subsequently she became increasingly restless. agitated, and mildly confused. L-Dopa, in a dose of $1.5 \mathrm{~g}$ daily, was similarly unsuccessful, and the patient was discharged, in an unchanged condition, in July, 1974.

From the beginning of 1976, the patient's husband noticed a change in her disabilities. She had difficulty looking down and, on bending her neck forwards, her eyes would tend to roll upwards. Her speech became confused and her walking unsteady. At times she was incontinent of urine and had difficulty swallowing.

On examination, in August, 1976, she was slow and had a poor memory; her speech was both dysarthric and dysphasic. Walking was slowed. with a tendency to festination, and her neck was rigid, particularly on flexion. Command and following eye movements were absent in the vertical plane, apart from a few degrees of following down movement. Convergence was absent. Horizontal movements to command to the right were limited to $10^{\circ}$. but improved with pursuit. Movements to the left were slowed but virtually full. Oculocephalic responses were normal apart from a slight reduction in the range of downward gaze. The fast phase of optokinetic nystagmus was absent in all directions. Caloric responses were not assessed. Facial movements were impoverished and, although reflex palatal activity was brisk, voluntary movements of the palate and tongue were slowed.

In the limbs, there was bilateral cogwheel rigidity and a paucity of voluntary movement. Grasp reflexes were prominent, the deep tendon reflexes exaggerated, and the plantar responses extensor. No impairment of sensation was detected, though cooperation was imperfect.

The general examination was normal apart from a persistent tachypnea.

Psychometry confirmed the clinical impression of a dementia, and revealed a non-fluent dysphasia with considerable perseveration. An electroencephalogram showed a diffuse excess of slow wave activity. Computerised axial tomography demonstrated dilated ventricles and cortical sulci. Formal neurootological assessment was not carried out. The patient's disabilities were uninfluenced by amantidine or combined L-Dopa with a dopa decarboxylase inhibitor and she was subsequently discharged.

\section{DISCUSSION}

The descriptions (Tellez-Nagel et al, 1973; Powell et al, 1974; Roy et al, 1974) of a specific electronmicroscopic appearance of the neurofibrillary tangles in the brain stem of patients with progressive supranuclear palsy have supported Steele's contention (1972) that the syndrome has a distinctive neuropathological pattern. This has, in turn, reinforced attempts to define a correspondingly distinct clinical picture and in the final stages of the disease, the diagnosis is inescapable. An essential requirement for such a diagnosis has been a characteristic ophthalmoplegia, as the other manifestations of the disease, though sometimes suggesting the diagnosis, are less than specific.

A rigidity and bradykinesia of the limbs, for example, may mimic those of idiopathic or post-encephalitic Parkinson's disease, though a characteristic tremor usually has been lacking. Generally, in progressive supranuclear palsy, these manifestations do not respond to dopa (as with cases, 1, 3, 4 and 5), but a moderate improvement has been recorded by some authors (Derenzi et al, 1969; Pfaffenbach et al, 1972; Mastaglia et al, 1973). It was seen by ourselves in case 2 of this series, both with dopa and with bromocriptine, a dopaminergic agonist. At times, a particular type of axial rigidity produces neck extension and suggests the diagnosis, but in many cases (and in 4 of the patients here) the increase of tone is more general, affecting neck flexors and extensors nearly equally. The presence of a pseudo-bulbar palsy and exaggerated deep tendon reflexes may further the resemblance to postencephalitic Parkinsonism, as may the development of disorders of respiratory rhythm.

In a review of respiratory disorders in epidemic encephalitis, Turner et al (1925) described both tachypnea and sighs, the latter being encountered particularly frequently. Though Steele (1972) failed to find, in his review of the literature of progressive supranuclear palsy, any example of respiratory arhythmia, Mastaglia et al (1973) noted inspirat- ory gasps in two patients (one of whom had intermittent tachypnea in addition), both otherwise typical examples of the syndrome. Three of our patients developed sudden gasps in the later stages of their illness. and one had a persistent tachypnea. though the possibility of a primary pulmonary cause for this was not excluded. None of these patients had their respiration recorded, and whether these gasps were of significance, or whether they differ from the physiological sighs occurring frequently in normal individuals (Bendixen et al, 1964) remains to be determined.

It has been suggested that in normal individuals sighing serves to reopen scattered areas of atelectasis caused by regional hypoventilation, and, conceivably, such areas might be more common in the presence of rigidity of the chest wall as may be encountered in progressive supranuclear palsy. If this were the case, however, similar findings would be expected in Parkinson's disease, whereas reports of breathing disorders in this condition have centered on the presence or absence of dyspnea (Nugent et al, 1958).

The diagnosis may be further obscured where cases show signs suggesting more focal lesions. Patients with a predominantly unilateral limb weakness have been previously described (David et al, 1968), and although dementia may become prominent (Steele, 1972), cases in which dysphasia has been the most striking part of such a dementia (cases 3 and 5) have not been previously reported. Albert et al (1974) claimed that disturbances of higher cortical function, including dysphasia, were conspicuously absent in the socalled 'sub-cortical dementia' of progressive supranuclear palsy. They suggested that the patients' verbal responses were always appropriate, providing sufficient time was allowed. In our two cases, however, spontaneous speech was markedly dysphasic, had been noted by the patients relatives, and was confirmed by formal psychometric assessment. Both had evidence of cortical atrophy on neuroradiological investigation. There are conflicting 
reports of the histological appearances of the cerebral cortex in patients with progressive supranuclear palsy. A normal appearance, the presence of occasional neurofibrillary tangles, and the presence of tangles in the hippocampus but not in the isocortex have all been recorded. Steele (1972) noted neurofibrillary tangles and granulovacular degeneration in the temporal cortex of one case. It might be argued that a small number of tangles, largely confined to the hippocampus, in some patients may be no more than would be expected in elderly patients, and that more extensive changes, if ever found, might simply represent the coexistence of progressive supranuclear palsy with either Alzheimer's disease or senile dementia. The question has been considered in detail by Ishino et al (1976) by examining the distribution of neurofibrillary tangles in the cerebral hemisphere in 2 patients. Their findings, that the number in the cerebral cortex (mainly the third layer) exceeded those found in the senile brain, that there were no accompanying senile plaques, and that there were morphological differences from the tangles of Alzheimer's disease or senile dementia led them to propose that the tangles found in the cerebral cortex may be one of the morphological manifestations of the disease. If this is so, the cortical atrophy found radiologically in two of our cases and by other authors at post-mortem examination (Tellez-Nagel et al, 1973; Powell et al, 1974) may represent something more than an unrelated chance finding. Disturbances of higher cortical function would, therefore, not be surprising as an occasional part of the clinical spectrum of the disease. Analysis of the ultrastructure of the tangles found in the cortex would help resolve this issue, since those studied in the brain stem have shown an unique pattern of straight tubules, either in isolation (Tellez-Nagel et al, 1973; Powell et al, 1974; Roy et al, 1974) or in association with twisted tubules of Alzheimer type (Tomonaga, 1977). Although Steele (1972) has conjectured on the role of aluminium in causation of the disease, ultrastructure of tangles produced experimentally by aluminium does not resemble the characteristic straight tubules found in progressive supranuclear palsy.

In view of the uncertainty as to the acceptability of disturbances of higher cortical function' within the spectrum of progressive supranuclear palsy, the role of the characteristic ophthalmoplegia in establishing the diagnosis is essential. Typically, an impairment of voluntary gaze, particularly in the vertical plane and initially with preservation of oculocephalic responses, is evident. A concomitant depression of the fast phase of vestibular-induced and optokinetic nystagmus (Newman et al, 1970; Dix et al, 1971) confirms the observations of Fox et al (1926) that these phenomena and voluntary saccades depend on the same anatomical pathway.

Problems in establishing the diagnosis are likely to arise, either when the ophthalmoplegia shows unusual features, or when it is absent in the initial stages of the disease. Spontaneous nystagmus, for example, may be present when the fast components of optokinetic and vestibular induced nystagmus are depressed (Dix et al, 1971; Pfaffenbach et al, 1972; Mastaglia et al, 1975). An internuclear component to the ophthalmoplegia could not be detected in a group of 44 patients assessed by Pfaffenbach et al (1972), but the presence of myelin loss in the medial longitudinal bundle at postmortem examination in a typical case of the syndrome (Blumenthal et al, 1969) suggested that a corresponding clinical disturbance would eventually be described.

Although photographs of the eye movements of a patient recorded by Mendell et al (1970) appear to show an internuclear ophthalmoplegia, the phenomenon was first specifically noted in 4 cases, by Mastaglia et al (1975.) These authors made the clinical observation that the internuclear component disappeared during the oculocephalic maneuvre, suggesting the possibility of separate pathways for volitional and vestibular-induced eye movements in the medial longitudinal bundle. The presence of an internuclear ophthalmoplegia in two of our patients would support its inclusion as a possible component of the ophthalmoplegia of this condition. Although, in one of these cases, the adduction paresis was thought to improve during the oculocephalic maneuvre, this could not be confirmed by electronystagmography. Daroff et al (1971) have stated that the amplitude of the adduction paresis in an internuclear ophthalmoplegia is never increased by oculocephalic or caloric stimulation.

An alternative explanation for the internuclear ophthalmoplegia, and its apparent improvement on the doll's head maneuvre, may exist. Newman et al (1970) demonstrated normal reciprocal inhibition for following movements, but not for refixation movements, in patients with progressive supranuclear palsy. Thus, during refixation movements, inconsistent and incomplete inhibition of antagonists occurred. If, during lateral saccades, inhibition was less complete for lateral as compared with medial rectus, an internuclear ophthalmoplegia would be simulated, which would not be demonstrable during following movements or with the doll's head maneuvre. Clearly, this explanation cannot suffice for either of our patients, as both showed an equal degree of adduction paresis for following as for refixation movements.

In addition to an internuclear ophthalmoplegia, case 2 showed other unusual features. Preservation of vestibular-induced nystagmus, eight years after the onset of symptoms, is surprising, particularly as, by then, horizontal saccades were impaired. This may simply reflect the late onset of the ophthalmoplegia in this case. The complex alternating nystagmus also recorded was of a type not previously reported in patients with progressive supranuclear palsy. Cases with periodic alternating nystagmus which have been examined at post-mortem have shown diffuse involvement of the caudal brain stem (Baloh et al, 1976).

The late development of the ophthalmoplegia in the course of the disease has previously been re- 
TABLE 1

RESULTS OF NEURO-OTOLOGICAL EXAMINATION

\begin{tabular}{|c|c|c|c|c|c|c|c|c|c|c|c|c|}
\hline 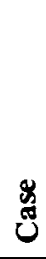 & 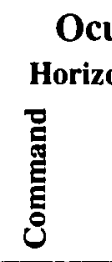 & $\begin{array}{c}\text { lar Mo } \\
\text { ntal } \\
\text { 产 } \\
\frac{\bar{a}}{\mathrm{a}}\end{array}$ & 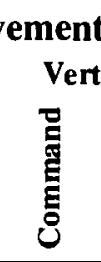 & $\stackrel{\frac{3}{0}}{\frac{3}{8}}$ & 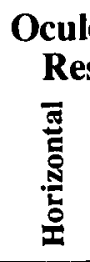 & 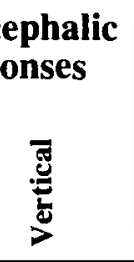 & 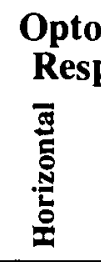 & 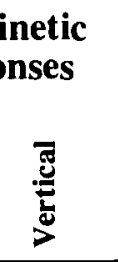 & 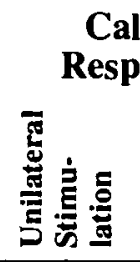 & 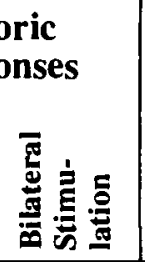 & 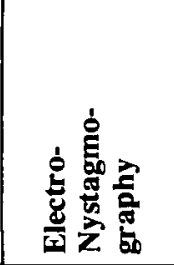 & 롤 \\
\hline 1 & $\begin{array}{l}\text { Slow } \\
\text { with } \\
\text { L.I.N.O. }\end{array}$ & $\begin{array}{l}\text { Slow } \\
\text { with } \\
\text { L.I.N.O. }\end{array}$ & Absent & $\begin{array}{l}5^{\circ} \mathrm{Up} \\
\text { Gaze } \\
\text { Only }\end{array}$ & Full & Full & $\begin{array}{l}\text { Absent } \\
\text { Fast } \\
\text { Phases } \\
\text { L.I.N.O }\end{array}$ & $\begin{array}{l}\text { Absent } \\
\text { Fast } \\
\text { Phases }\end{array}$ & $\begin{array}{l}\text { Slow Drift } \\
\text { No } \\
\text { Nystagmus }\end{array}$ & $\begin{array}{l}\text { Slow Drift } \\
\text { No } \\
\text { Nystagmus }\end{array}$ & $\begin{array}{l}\text { Confirmed } \\
\text { Clinical } \\
\text { Observations }\end{array}$ & Normal \\
\hline 2 & $\begin{array}{l}\text { Slow } \\
\text { with } \\
\text { L.I.N.O. } \\
\text { and } \\
\text { Nystag. }\end{array}$ & $\begin{array}{l}\text { Slow } \\
\text { with } \\
\text { L.I.N.O. } \\
\text { and } \\
\text { Nystag. }\end{array}$ & $5^{\circ}$ & $5^{\circ}$ & Full & $\begin{array}{l}\text { Range of } \\
\text { Movement } \\
\text { Improved }\end{array}$ & $\begin{array}{l}\text { Absent } \\
\text { Fast } \\
\text { Phases }\end{array}$ & $\begin{array}{l}\text { Nystag. } \\
\text { to } R . \\
\text { and Up- } \\
\text { wards } \\
\text { on Down } \\
\text { Rotatiom }\end{array}$ & Normal & $\begin{array}{l}\text { No Nystag. } \\
\text { Improved } \\
\text { Range of } \\
\text { Movement }\end{array}$ & $\begin{array}{l}\text { Probable } \\
\text { Bilateral } \\
\text { Internuclear } \\
\text { Ophthalmo- } \\
\text { plegia. } \\
\text { Alternat. } \\
\text { Nystag. on } \\
\text { Prima:y Gaze } \\
\text { Unaffected } \\
\text { by Eye Clos. } \\
\text { or Carkness }\end{array}$ & $\begin{array}{l}\text { High Tone } \\
\text { Loss } \\
\text { Bilaterally }\end{array}$ \\
\hline 3 & $\begin{array}{l}\text { Slow } \\
\text { Reduced } \\
\text { Range }\end{array}$ & $\begin{array}{l}\text { Improv. } \\
\text { Range } \\
\text { but } \\
\text { Incompl. } \\
\text { \& Slow }\end{array}$ & Absent & $\begin{array}{l}20^{\circ} \mathrm{Up}_{\mathrm{p}} \\
\text { Gaze }\end{array}$ & Full & Full & $\begin{array}{l}\text { Irreg. } \\
\text { Nystag. } \\
\text { with } \\
\text { Drum } \\
\text { Rotat. } \\
\text { to L. }\end{array}$ & $\begin{array}{l}\text { Absent } \\
\text { Fast } \\
\text { Phases }\end{array}$ & $\begin{array}{l}\text { Slow } \\
\text { Drift } \\
\text { No } \\
\text { Nystag. }\end{array}$ & $\begin{array}{l}\text { Slow } \\
\text { Drift } \\
\text { No } \\
\text { Nystag. }\end{array}$ & $\begin{array}{l}\text { Not } \\
\text { Performed }\end{array}$ & $\begin{array}{l}\text { Not } \\
\text { Performed }\end{array}$ \\
\hline 4 & $\begin{array}{l}\text { Slow } \\
\text { Reduced } \\
\text { to L. }\end{array}$ & Slow & $\begin{array}{l}\text { Absent } \\
\text { Up } \\
\text { Gaze \& } \\
\text { Reduc. } \\
\text { Down }\end{array}$ & $\begin{array}{l}\text { Absent } \\
\text { Up } \\
\text { Gaze \& } \\
\text { Reduc. } \\
\text { Down }\end{array}$ & Full & Full & $\begin{array}{l}\text { Absent } \\
\text { Fast } \\
\text { Phases }\end{array}$ & $\begin{array}{l}\text { Absent } \\
\text { Fast } \\
\text { Phases }\end{array}$ & $\begin{array}{l}\text { Weak } \\
\text { Fast } \\
\text { Phase } \\
\text { with } \\
\text { Slow Drift }\end{array}$ & $\begin{array}{l}\text { Slow Drift } \\
\text { No } \\
\text { Nystagmus }\end{array}$ & $\begin{array}{l}\text { Not } \\
\text { Performed }\end{array}$ & $\begin{array}{l}\text { Bilateral } \\
\text { Perceptive } \\
\text { Deafness } \\
\text { More on } \mathbf{R}\end{array}$ \\
\hline
\end{tabular}

L.I.N.O. = Left Internuclear Ophthalmoplegia. $\quad{ }^{*}$ The details for Case 4 relate to the first admission in 1973. 
corded by Pfaffenbach et al (1972). In six of their patients, an initial diagnosis of bradykinetic Parkinsonism had been made and symptoms were present for eight to twelve years in five of these cases before the correct diagnosis was established. Ocular symptoms and signs had thus developed three to nine years after the onset of other neurological symptoms.

Similarly, the fifth case of Albert et al (1974) presented with a general slowing of thought and activity, with increased apathy and irritability. Three years after the onset, there were Parkinsonian signs but no ophthalmoplegia, and the latter was not noted until eighteen months later. None of our patients had ocular symptoms at the time of presentation. Four had no ocular signs, and in the fifth, those present consisted of a slowing of horizontal and vertical movements without paresis. In the other four patients, ocular signs only became apparent after the disease had been present for eight, eight, three and three years respectively. The late de velopment of ocular signs had led to erroneous diagnoses in all. Cases 1, 2 and 5 were considered examples of idiopathic Parkinson's disease, case 3 was considered to have a degenerative disorder of unknown etiology, and case 4 was initially treated, at another hospital, with antidepressant and electroconvulsive therapy on the assumption that his symptoms had a depressive basis. Two cases (4 and $5)$, therefore, had received electroconvulsive therapy, and in both the treatment appeared to accelerate the clinical course.

The four surviving patients reported have now had the disease for seven, nine, four and four years, and a similar length of history was apparent in those patients described by Pfaffenbach et al. (1972) where the ophthalmoplegia was not a presenting feature. Conceivably, cases of this nature may have a milder form of the disease, since in Steel's review (1972) of the subject the majority of patients were dead within seven years of the onset.

The descriptions of cases resembling progressive supranuclear palsy in the literature of the early part of this century (Spiller, 1905; Janischewsky, 1909; Alajouanine et al, 1926; Cornil et al, 1929; Francais et al, 1932) led Behrman et al (1969) to suggest that the syndrome might be a sequel of encephalitis lethargica, though several of these reports antedated the known pandemics of encephalitis. Support for such a concept would be forthcoming if these cases had had evidence of a preceding encephalitic illness, which, however, they had not. Description of eye movement disorders in patients with encephalitis lethargica (Hall, 1924; Critchley, 1928) or with postencephalitic Parkinsonism (Goldbach, 1929; Crow, 1949) lack examples of supranuclear ophthalmoplegia. One of us (A.J.L.) has examined the eye movements of forty patients with post-encephalitic Parkinsonism at the Highlands Hospital. Although two cases showed a partial failure of vertical gaze, improving with the doll's head maneuvre, the clinical picture in each was dominated by tremor and multiple tics. Similarly, in a case of supranuclear ophthalmoplegia described by Ford et al (1936), with post-mortem changes suggesting epidemic encephalitis, the brief total duration of the illness (ten months) and the other clinical features (convergence spasm and facial myoclonic jerks) serve to distinguish the case clinically from progressive supranuclear palsy.

Using electronystagmography, Slatt et al (1966) demonstrated a relative preservation of pursuit as opposed to voluntary horizontal gaze in eight patients with Parkinson's disease. The majority of these were said to be arteriosclerotic in origin. Corin et al (1972) contrasted the frequent involvement of voluntary, as opposed to oculocephalic, eye movements in a group of seventy Parkinsonian patients and suggested that there might be a continuous spectrum of clinical disorders between typical examples of idopathic Parkinson's disease and progressive supranuclear palsy.

Clearly, such a diagnostic uncertainty may arise in the early stages of progressive supranuclear palsy, where the ophthalmoplegia is inconspicuous, and may in turn lead to the consideration of alternative disorders, as happened in all five cases here. The use of electronystagmography may be of value at this stage, though, the oculomotor findings in the early stages may well be indistinguishable from those of Parkinson's disease.

An investigation of auditoryevoked responses may be of more value. Clinical deafness is not a feature of idiopathic Parkinson's disease, but appears relatively common in progressive supranuclear palsy (Dix et al, 1971), and was detected by audiometry in three of four patients investigated by ourselves. Steele (1972) did not comment on changes in the cochlear nuclei at post-mortem examination in four cases, but did note abnormalities in the superior olive. The five components of the auditory evoked responses have been tentatively alloted to differing levels in the auditory pathways in the brain stem (Thornton et al, 1976), including the superior olive. The degenerative changes encountered in progressive supranuclear palsy would appear more likely to depress the amplitude of these responses than cause an alteration in latencies. Other pointers to the correct diagnosis may also exist in the early stages, either from the presence of pyramidal signs, an overt dementia, or a lack of response to dopa therapy. Once the ophthalmoplegia has developed, the correct diagnosis can be assigned with confidence, serving to identify a syndrome which on both clinical and pathological grounds appears distinct.

\section{ACKNOWLEDGMENTS}

We wish to thank Dr. J. Sharkey, Consultant Geriatrician, for permission to study patients under his care at the Highlands Hospital, and Dr. P. Gautier-Smith for allowing us to publish details of case 5 , a patient admitted under his care.

\section{REFERENCES}

ALAJOUANINE, T., DELAFONTAINE, P., LACAN, J. (1926) Fixite du regard par hypertome, predominant dans les sensevertical, avec conservation des mouvements automatico-reflexes, aspect special de syndrome de parinaud par hypertonie associee a un syndrome extrapyramidal avec trou- 
bles pseudobulbaires. Revue Neurologique 33, 410-418.

ALBERT, M. L., FELDMAN, R. G., and WILLIS, A. L. (1974). The 'subcortical dementia' of progressive supranuclear palsy. Journal of Neurology, Neurosurgery and Psychiatry $37,121-130$.

BALOH, R. W., HONRUBIA, V., and KONRAD, H. R. (1976). Periodic alternating nystagmus. Brain 99, 11-26.

BEHRMAN, S., CARROLL, J. D., JANOTA, I., and MATTHEWS, W. B. (1969). Progressive supranuclear palsy. Clinico-pathological study of four cases. Brain 92, 663-678.

BENDIXEN, H. H., SMITH, G. M., and MEAD, J. (1964). Pattern of ventilation in young adults. Journal of Applied Physiology 19, 195-198.

BLUMENTHAL, H. and MILLER, C. (1969). Motor nuclear involvement in progressive supranuclear palsy. Archives of Neurology 20, 362-367.

CORIN, M. S., ELIZAN, T. S. and BENDER, M. B. (1972). Oculomotor function in patients with Parkinson's disease. Journal of the Neurological Sciences 15, 251-265.

CORNIL, L. and KISSEL, P. (1929). Syndrome extra-pyramidal avec paralysie verticale du regard et conservation des mouvements automatico-reflexes. Remarques sur les synergies oculo-palpebrales du syndrome de parinaud. Revue Neurologique $36,1189-1191$.

CRITCHLEY, A. M. (1928). Ocular manifestations following encephalitis lethargica. The Bristol Medico-Chirurgical Journal 45, 113-124.

CROW, J. (1949). A note on certain ocular phenomena of post-encephalitic Parkinsonism. Glasgow Medical Journal 30, 29-34.

DAROFF, R. B. and HOYT, W. F. (1971) The control of eye movements. New York and London Academic Press. Edited by Bach-Y-Rita, P., Collins, C. C., Hyde, J. E. Supranuclear disorders of ocular control systems in man. Clinical, anatomical and physiological correlations. 1969. Pages 175-235.

DAVID, N. J., MACKEY, E. A. and SMITH, J. L. (1968). Further observations in progressive supranuclear palsy. Neurology, Minneapolis 18, 349-356.

DERENZI, E. and VIGNOLO, L. A. (1969). L-Dopa for progessive supranuclear palsy, Lancet 2, 1359.

DIX, M. R., HARRISON, M. J. G. and LEWIS, P. D. (1971). Progressive sup- ranuclear palsy (the Steele-RichardsonOlszewski syndrome). A report of 9 cases with particular reference to the mechanism of the oculomotor disorder. Journal of the Neurological Sciences, 13, 237-256.

FORD, F. R. and WALSH, F. B. (1936). Clinical observations upon the importance of the vestibular reflexes in ocular movements. The effects of section of one or both vestibular nerves. Bulletin of the John Hopkins Hospital 58, 80-88.

FOX, J. C. and HOLMES, G. (1926). Optic nystagmus and its value in the localization of cerebral lesions. Brain 49, 333-371.

FRANCAIS. H. and VERNOTTE, S. (1932). Syndrome de parinaud associe a un synđrome de rigidite extra pyramidale. Revue D'Oto-Neuro-Ophthalmologie 10, 739-741.

GOLDBACH, L. J. (1929). Eye symptoms and the Parkinsonian syndrome. Archives of Ophthalmology 2, 555-559.

HALL, A. J. (1924). Epidemic encephalitis. Bristol, London. John Wright \& Sons Ltd.

ISHINO, H., OTSUKI, S. (1976). Frequency of Alzheimer's neurofibrillary tangles in the cerebral cortex in progressive supranuclear palsy. (Subcortical Argyrophilic Dystrophy). Journal of the Neurological Sciences, 28, 309-316.

JANISCHEWSKY, A. (1909). Un cas de maladie de Parkinson avec syndrome pseudo-bulbaire et pseudo-ophthalmoplegique. Quelques considerations sur la pathogenie de cette maladie. Revue Neurologique 17, 823-831.

MASTAGLIA, F. L., GRAINGER, K.. KEE, F., SADKA, M. and LEFROY, R. (1973). Progressive supranuclear palsy (The Steele-Richardson-Olszewski syndrome). Clinical and electrophysiological observations in eleven cases. Proceedings of the Australian Association of Neurology 10 , 35-44.

MASTAGLiA, F. L. and GRAINGER, K. M. R. (1975). Internuclear ophthalmoplegia in progressive supranuclear palsy. Journal of the Neurological Sciences 25, 303-308.

MENDELL, J. R., CHASE, T. N. and ENGEL, W. K. (1970). Modification by L-Dopa of a case of progressive supranuclear palsy with evidence of defective cerebral dopamine metabolism. Lancet 1. 593-594.

NEWMAN, N., GAY, A. J., STROUD, M. H. and BROOKS, J. (1970). Defective rapid eye movements in progressive supranuclear palsy. An ocular electromyographic study. Brain 93, 775-784.
NUGENT, C. A., HARRIS, H. W., COHN, J.. SMITH. C. C. and TYLER, F. $H$. (1958). Dyspnea as a symptom in Parkinson's syndrome. American Review of Tuberculosis 78, 682-691.

PFAFFENBACH, D. D., LAYTON, D. D. and KEARNS, T. P. (1972). Ocular manifestations in progressive supranuclear palsy. American Journal of Opthalmology 74, 1179-1184.

POWELL, H. C., LONDON. G. W. and LAMPERT, P. W. (1974). Neurofibrillary tangles in progressive supranuclear palsy: electron microscopic observations. Journal of Neuropathology and Experimental Neurology 33, 98-106.

RICHARDSON. J. C., STEELE, J. and OLSZEWSK1. J., (1963). Supranuclear Ophthalmoplegia, Pseudobulbar Palsy. Nuchal Dystonia and Dementia. Trans. Am. Neurol. Assoc. 88, 25-27.

ROY, S., DATTA, C. K.. HIRANO, A., GHATAK, N. R. and ZIMMERMAN, H. M. (1974). Electron microscopic study of neurofibrillary tangles in SteeleRichardson-Olszewski Syndrome. Acta Neuropathologica (Berlin) 29, 175-179.

SLATT, B., LOEFFLER, J. D. and HOYT, W. F. (1966). Ocular motor disturbances in Parkinson's disease. Electromyographic observations. Canadian Journal of Ophthalmology 1, 267-273.

SPILLER. W. G. (1905). The importance in clinical diagnosis of paralysis of associated movements of the eyeballs (Blicklaehmung), especially of upward and downward associated movements. The Journal of Nervous and Mental Diseases 32, 417-448 and 497.530.

STEELE. J. C. (1972). Progressive supranuclear palsy. Brain 95, 693-704.

TELLEZ-NAGEL, I. and WISNIEWSKI. H. M. (1973). Ultrastructure of neurofibrillary tangles in Steele-RichardsonOlszewski syndrome. Archives of Neirology $29,324-327$.

THORNTON, A. R. D. and HAWKES, C. H. (1976). Neurological applications of surface-recorded electrocochleography. Journal of Neurology, Neurosurgery and Psychiatry 39, 586-592.

TOMONAGA M. (1977). Ultrastructure of neurofibrillary tangles in progressive supranuclear palsy. Acta Neuropathologica (Berlin) 37. 177-181.

TURNER, W. A. and CRITCHLEY, M. (1925). Respiratory disorders in epidemic encephalitis. Brain $48,72-104$. 